\title{
Production of Emulsion House Paint Using Polyvinyl Acetate and Gum Arabic as Binder
}

\author{
Surajudeen Abdulsalam*, Zebulu Dauma Maiwada \\ Department of Chemical Engineering, Faculty of Engineering \& Engineering Technology, Abubakar Tafawa Balewa University Bauchi, \\ Bauchi-Nigeria
}

\section{Email address:}

surajudeen_abdulsalam@yahoo.com (S. Abdulsalam), zebulunolimit@gmail.com (Z. D. Maiwada)

\section{To cite this article:}

Surajudeen Abdulsalam, Zebulu Dauma Maiwada. Production of Emulsion House Paint Using Polyvinyl Acetate and Gum Arabic as Binder. International Journal of Materials Science and Applications. Vol. 4, No. 5, 2015, pp. 350-353. doi: 10.11648/j.ijmsa.20150405.20

\begin{abstract}
In view of the high cost of paints as a result of importation of raw materials and the need to use our locally available raw materials for economic and industrial developments, a study was carried out for the production of emulsion house paint by supplementing imported synthetic binder (polyvinyl acetate, PVA) with a locally available binder (gum Arabic, GA) in six different proportions labelled; Sample A (100\% PVA), Sample B (80\% PVA: 20\% GA), Sample C (60\% PVA: 40\% GA), Sample D (40\% PVA: $60 \%$ GA), Sample E (20\% PVA: $80 \%$ GA) and Sample F (100\% GA). Standard emulsion paint formulation and method of production were employed. All the six samples gave high quality emulsion paints in terms of opacity, adhesion, ease of application and coverage. However, it was observed that paint brightness diminished with increased gum Arabic composition; Sample F being badly affected. Samples B to E thus resulted in quality paints without any blemish. Therefore, gum Arabic (Acacia Senegal) can be used as a supplement to PVA in emulsion paint production in all proportions investigated except Sample F.
\end{abstract}

Keywords: High Cost, Supplement, Quality Parameters, Polyvinyl Acetate, Gum Arabic, Emulsion Paint

\section{Introduction}

The terms 'paint' and 'surface coating' are often used interchangeably. Surface coating is the more general description of any material that may be applied as a thin continuous layer to a surface. Paint was traditionally used to describe pigmented materials as distinct from clear films which are more properly called lacquers or varnishes [1]. Paint is a loosely word covering a whole variety of materials; enamels, lacquers, varnishes, undercoats, surfacers, primers, sealers, fillers, stoppers and many others. If the pigment is omitted, the material is usually called a varnish [2]. The pigmented varnish - the paint - is sometimes called an enamel, lacquer, finish or topcoat, meaning that it is the last coat to be applied and the one seen when the coated object is examined.

Paints and coatings can be classified into the following major categories; architectural coatings, product coatings for original equipment manufacturers and special purpose coatings [3]. Of these three major categories, emulsion house paints fall in the first category. Therefore, emphasis was given to this class.

Emulsion house paint is a water based paint principally used for internal and external surface coatings, mostly in buildings for appearance and protection. The processes involved in paint production, quality and performance of emulsion paint depends largely on the properties of its constituents and the ratios of these constitutions. The constituents generally used for the production of emulsion house paints include; prime pigments, solvents, extenders pigments, binders and additives [4].

In the constituents for production of emulsion house paints, binder (PVA) usually takes between 17 to $33 \%$ total cost of production depending on paint type and this raw material is not available locally, therefore imported. Hence, high cost of this raw material (binder) and consequently high cost of production due to the use of expensive binder. In addition, PVA is not environmentally friendly because of its non-biodegradability which can contaminate the environment if not properly handled. This is because PVA releases toxic fumes when burned. It can be hazardous to the environment, especially if it is mixed with water and comes in contact with fish [5].

Polyvinyl acetate, PVA, poly (ethenyl ethanoate), poly (1-acetyloxiethylene) is a rubbery synthetic polymer with the formula $\left(\mathrm{C}_{4} \mathrm{H}_{6} \mathrm{O}_{2}\right)_{\mathrm{n}}$. it has a molar mass of $86.09 \mathrm{~g} / \mathrm{mol} / \mathrm{unit}$. It belongs to the polyvinyl esters family with the general formula: $\mathrm{RCOOCHCH}_{2}$. It is a type of thermoplastic [6]. It is used as an emulsion in water, and as a binder in paints and coatings. PVA 
emulsions are used as adhesives for porous materials, particularly for wood, paper, and cloth, and as a consolidant for porous building stone, in particular sandstone [7].

Gum Arabic, also known as acacia gum, chaar gund, char goond, or meska, is a natural gum made of hardened sap taken from two species of the acacia tree; Acacia Senegal and Acacia Seyal. The gum is harvested commercially from wild trees throughout the Sahel from Senegal and Sudan to Somalia although it has been historically cultivated in Arabia and West Asia. Gum Arabic is a complex mixture of glycoproteins and polysaccharides. It was historically the source of the sugars arabinose and ribose, both of which were first discovered and isolated from it, and are named after it.

Gum Arabic is used as a binder for watercolor painting because it dissolves easily in water. Pigment of any color is suspended within the acacia gum in varying amounts, resulting in watercolor paint. Water acts as a vehicle or a diluent to thin the watercolor paint and helps to transfer the paint to a surface such as paper. When all moisture evaporates, the acacia gum binds the pigment to the paper surface. After the water evaporates, the acacia gum in the paint film increases luminosity and helps prevent the colors from lightening. Gum Arabic allows more precise control over washes, because it prevents them from flowing or bleeding beyond the brush stroke.

In addition, acacia gum slows evaporation of water, giving slightly longer working time. Powdered gum Arabic for artists, one part gum Arabic is dissolved in four parts distilled water to make a liquid suitable for adding to pigments. It is also used in photography, printmaking and food industries.

Due to the aforementioned problems, the aim of the study was to produce emulsion house saints using PVA and GA as binder. The objectives were; to determine the effectiveness of gum Arabic as binder in 'Emulsion House Paint' and to determine the quality parameters of the produced paint.

The production of emulsion house paint using gum Arabic as supplement binder will definitely alleviate the problems of unavailability and high cost of PVA, increase cultivation of gum Arabic and add value to the agricultural produce due to increase in demand, and on a long run saves as means of creating employment. In addition, it will also reduce the hazard to the environment.

This research is limited to the production of emulsion house paint using a single grade of Gum Arabic (i.e. grade 1. Acacia Senegal) as supplement binder to polyvinyl acetate and to carry out the quality parameters tests on thee produced paint. These parameters include: viscosity, $\mathrm{pH}$, binding strength, coverage and brightness.

\section{Materials and Methods}

\subsection{Raw Materials}

Raw materials used for the production of emulsion paint were purchased from Sunny Wax International Agency, Panteka Market Kaduna, Kaduna State-Nigeria. Except the grade 1 gum Arabic (Acacia Senegal) that was obtained from
Muda-Lawal Market Bauchi, Bauchi State-Nigeria. List of materials, their brands and a typical 'Emulsion House Paint' formulation are presented in Table 1.

Table 1. Raw materials and formulation of a typical emulsion house paint.

\begin{tabular}{lll}
\hline Raw Material & Brand & Quantity \\
\hline Water (L) & - & 2.160000 \\
Polyvinyl acetate (L) & Pexi Chem Priveate Ltd, & 0.500000 \\
Gum Arabic & New Delhi & \\
Calcium carbonate (kg) & Grade 1 (Acacia Senegal) & - \\
Titanium dioxide (kg) & Calco, Freedom Groups & 2.040000 \\
Sodium tripolyphosphate(kg) & Du Pont Ti Pure & 0.560000 \\
Antifoam (kg) & Innophos & 0.000166 \\
Texanol (kg) & SAF 130 & 0.000166 \\
Genepor (kg) & East Man Texanol ${ }^{\mathrm{TM}}$ & 0.016600 \\
Formalin & Drugbrand DB00305 & 0.006670 \\
Ammonia, (28\%) (L) & Bamboo Charcoal & 0.500000 \\
Thickener (Natrosol) $(\mathrm{kg})$ & Technology & Bird Brand Ammonia \\
Total (L) & Natrosol Performax & 0.016600 \\
\hline
\end{tabular}

Source of formulation: Anonymous [8]

\section{Gum Arabic Solution Preparation}

Gum Arabic exudate was oven dried for six hours $(6 \mathrm{~h})$ then allowed to cool. Dirt and other foreign materials were removed from the dried exudates by hand picking. The screened gum Arabic was ground using mortar and pestle and sieved using a sieve stack consisting of $600 \mu \mathrm{m}, 425 \mu \mathrm{m}$, $300 \mu \mathrm{m}$ and the receiver. $1.3 \mathrm{~kg}$ of the ground gum Arabic powder was dissolved in $2 \mathrm{~L}$ of distilled water for $24 \mathrm{~h}$ to produce a $65 \% \mathrm{wt} / \mathrm{v}$ solution. This concentration was chosen in order to obtain a binding strength same as that of PVA (i.e. to save as basis for comparison).

\subsection{Procedure for Paint Production}

Two point one-six liters $(2.16 \mathrm{~L})$ of water was measured into a mixer; the stirrer (Model 50111, Type RZR1), then it was switched on. Measured amount of calcium carbonate as indicated in Table 1 was gradually dispersed into the mixing tank and allowed to grind for 5 min. Measured amounts of titanium dioxide and STPP as indicated in Table 1 were then dispersed and allowed to grind for another $10 \mathrm{~min}$ and other ingredients were added as itemized in Table 1 in their measured quantities. It should be noted that the thickener was added gradually, after which the mixture was allowed to grind properly before packaging.

\subsection{Quality Parameters Tests of Paints Produced}

Quality parameters tests were carried out on the six paint samples produced using the following methods; viscosity [9], binding strength (using testometric 200), $\mathrm{pH}$ (digital $\mathrm{pH}$ meter), and brightness (visual observation). Procedure for paint coverage is as follows;

Paint Coverage

Ceiling board was used for the paint coverage; the width and length of the ceiling board were 60.5 and $81.3 \mathrm{~cm}$ respectively which gave a surface area of $4918.65 \mathrm{~cm}^{2}$ 
$\left(0.492 \mathrm{~m}^{2}\right)$. Sixty milliliters $(60 \mathrm{ml})$ of the paint sample were used to paint the surface and the area of the ceiling board that was painted was recorded for each sample.

\section{Results and Discussion}

\section{1. pH of Paint}

From Table 2, pH values of paint samples produced fell within the specified range by the Standard Organization of Nigeria (SON) [10]. From these results obtained, sample A had a $\mathrm{pH}$ of 9.05 while samples $\mathrm{B}, \mathrm{C}, \mathrm{D}, \mathrm{E}$ and $\mathrm{F}$ had $\mathrm{pH}$ values of 7.62, 7.27, 7.32, 7.50 and 7.35 respectively. Samples that had gum Arabic solution in their compositions had lower $\mathrm{pH}$ values as compared to sample $\mathrm{A}$. These differences in $\mathrm{pH}$ values are attributed to differences in $\mathrm{pH}$ values of PVA and gum Arabic; PVA has a $\mathrm{pH}$ value of 5-6.5 [11] while gum Arabic has a $\mathrm{pH}$ value of 4.5-5.0 [12]; this shows that gum Arabic is slightly more acidic than PVA.

Samples B, C, D, E and F had $\mathrm{pH}$ values between 7.27 and 7.62, which is within the $\mathrm{pH}$ range where bacteria strives [13], therefore they are susceptible to bacterial attack because of favorable environment to strive. Hence, microbial growths were observed in all samples three months after production except in Sample A. To address this problem, the $\mathrm{pH}$ value for all the Samples affected have to be adjusted to 9.0 using ammonia solution.

Table 2. pH and viscosity of paints.

\begin{tabular}{lll}
\hline Sample & $\mathbf{p H}$ & Bacteria growth \\
\hline A & 9.05 & NG \\
B & 7.62 & GP \\
C & 7.27 & GP \\
D & 7.32 & GP \\
E & 7.50 & GP \\
F & 7.35 & GP \\
\hline
\end{tabular}

NG: no growth; GP: growth present.

\subsection{Viscosity of Paint}

Table 3 shows the viscosities of various paint samples, it could be seen that gum Arabic solutions have effects on their viscosities; the higher the proportion of GA in the paint, the higher its viscosity and vice versa [4]. The use of proper paint viscosity is critical for obtaining a quality finish; excessive viscosity can cause orange peel while a low viscosity can create a film that is too wet and creates runs [14]. According to ASTM D1200-70 [9], the effluent time for viscosity measurement of emulsion paints should fall between 40 and $100 \mathrm{~s}$ at temperature of between 20 and $30^{\circ} \mathrm{C}$ using a Ford viscosity cup. The paint samples had effluent times above 100 $\mathrm{s}$ and this is attributed to disparity between the orifices of the laboratory funnel used and that of Ford viscosity cup. However, since 'Sample A' is the 'Control', it gives the basis for comparison. The paint samples displayed good flow and ease of application which can be attributed their viscosities. However, to control these viscosities to the acceptable range or value, the quantity of thickener used in various paint sample must be reduced, hence, reduction in cost of production.

Table 3. Viscosity and binding strength of paints.

\begin{tabular}{lll}
\hline Sample & Viscosity (s) & B.stgth (kgf) \\
\hline A & $103 \pm 1.73$ & $0.66 \pm 0.16$ \\
B & $113 \pm 0.82$ & $0.60 \pm 0.07$ \\
C & $153 \pm 7.85$ & $0.68 \pm 0.08$ \\
D & $157 \pm 2.08$ & $0.56 \pm 0.06$ \\
E & $127 \pm 4.24$ & $0.82 \pm 0.07$ \\
F & $132 \pm 1.41$ & $0.81 \pm 0.21$ \\
\hline
\end{tabular}

B.stgth: Binding strength

\subsection{Binding Strength of Paint}

Binding strengths of the six samples are presented in Table 3 , as the proportion of GA increased in a sample, there was corresponding increase in binding strength except for samples $\mathrm{B}$ and $\mathrm{D}$ which had binding strengths of 0.60 and $0.56 \mathrm{kgf}$ respectively, which is less than the Control (Sample A). This may be attributed to experimental errors. The durability and performance of paint coatings depend on two basic properties; cohesion and adhesion [14]. The test conducted tested both cohesion and adhesion of the paint samples and the interfacial bonds showed that the paint samples have good binding strengths. This was confirmed by a good adhesion of the paint when it was used on a substrate. The painted boards showed no chalking effects two months after applications.

\subsection{Coverage of Paint}

The result in Table 4 shows that equal volume of paint covered equal surface area of the ceiling boards used for analyses. Sample A was adjudged to have the best coverage while samples B, C, D, $\mathrm{E}$ and $\mathrm{F}$ had better coverages. However, as the proportion of GA increased in the paint samples, it brightness diminished, Sample $\mathrm{F}$ being affected the most. This in no doubt is attributed to the brownish color of gum Arabic which is in contrast to the whitish color of PVA. This result showed that $60 \mathrm{ml}(0.06 \mathrm{~L})$ of paint samples gave adequate coverages for the six samples (covered an area of $0.492 \mathrm{~m}^{2}$ ). From this result, it can be deduced that $1 \mathrm{~L}$ will cover a surface area of $8.2 \mathrm{~m}^{2}$ of ceiling board which conforms to NIS 269 as in [10].

Table 4. Coverage and brightness of paints.

\begin{tabular}{lll}
\hline Sample & Coverage $\left(\mathbf{m}^{\mathbf{2}}\right)$ & Brightness \\
\hline A & 0.492 & Excellent \\
B & 0.492 & Excellent \\
C & 0.492 & Very good \\
D & 0.492 & Good \\
E & 0.492 & Fairly good \\
F & 0.492 & Fair \\
\hline
\end{tabular}

\section{Conclusions and Recommendations}

From the results obtained in this study, the following conclusions and recommendations were drawn; Gum Arabic (Acacia Senegal) can be used as an effective supplement binder to polyvinyl acetate in PVA to GA ratios of $80: 20 \%$; $60: 40 \%, 40: 60 \%$ and 20:80\% without compromising standard 
for the production of emulsion house paint. Since the cost of GA is less than that of PVA taken at an equivalent basis, blending both types of binders will definitely lead to cost reduction; Sample E being the most cost effective, followed by Samples D, C and B respectively. All the blends except Sample A (PVA-100\%: GA-0\%) were susceptible to bacteria growth three months after production (Table 2), therefore the $\mathrm{pH}$ values for these Samples should be adjusted to 9.0. In addition, the findings of this study can be scale-up for the production of cost-effective emulsion house paint.

\section{References}

[1] R. Lambourne, "Paint and Surface Coatings: Theory and Practice”, Ellis Horwood Limited. New York. Pp. 25-29, 35-39, 1988.

[2] G. P. A. Turner, "Introduction to Paint Chemistry and Principles of Paint Technology", Third Edition. Chapman and Hall. London. pp. 85-88, 1990.

[3] J. C. Dean, "Coatings: the U. S Coatings Industry Strategy for Survival in the 80's", the Chem Week, Volume 29, 1981.

[4] S. Abdulsalam, and Yahaya, Y. U. (2010), "Effectiveness of Gum Arabic as a Binder in Emulsion House Paint", Global Journal of Engineering Research, 10 (1 \& 2): pp. 83-89, 2010.
[5] Http. 1 (2014): http://www.ehow.com/list 7641940 properties-pva. Retrieved on $10^{\text {th }}$ March, 2014.

[6] G. T. Murray, "Handbook of Materials Selection for Engineering Applications” CRC Press, pp. 242, 1997.

[7] M. E. Young, M. Murray and P. Cordiner, "Stone Consolidants and Treatments in Scotland", Robert Gordon University, 1999.

[8] Anonymous (2014). "Emulsion Paint Formulation. Baygo Consult Nig. Enterprises".

[9] Annual Book of ASTM Standards, "Paint Test for Formulated Products and Applied Coatings" Part 27. ASTM 1916 Race St., Philadelphia, Pa. 19103. Pp. 393-394, 397, 1982.

[10] T. Rodger, "Paint Technology Handbook", CRC Press. pp. 82, 2007.

[11] Nigerian Industrial Standard "Specifications for Emulsion Paints for Decorative Purposes", Standards Organisation of Nigeria. ICS: 87.040, 2008.

[12] S. K. Saxena, "Polyvinyl Alcohol (PVA) Chemical and Technical Assessment (CTA)", 61 $1^{\text {st }}$ JECFA, FAO, 2004.

[13] A. Jumbo "Gum Arabic an Ancient Ingredient for the $22^{\text {nd }}$ Century", American Journal of Clinical Nutrition. Vol. 63. pp. 392-398, 1996.

[14] J. E. Bailey and D. F. Ollis, "Biochemical Engineering Fundamentals", International Student Edition, McGraw-Hill Kogakusha, Ltd, New Delhi, 1977. 